\title{
Predicting falls in residential care by a risk assessment tool, staff judgement, and history of falls
}

\author{
Lillemor Lundin-Olsson, Jane Jensen, Lars Nyberg, and Yngve Gustafson \\ Department of Community Medicine and Rehabilitation, Physiotherapy and Geriatric Medicine, Umeå \\ University, Umeå, Sweden
}

\begin{abstract}
Background and aims: It is of great importance to consider whether a tool's predictive value is generalizable to similar samples in other locations. Numerous fall prediction systems have been developed, but very few are evaluated over a different time period in a different location. The purpose of this study was to validate the predictive accuracy of the Mobility Interaction Fall (MIF) chart, and to compare it to staff judgement of fall risk and history of falls. Methods: The MIF chart, staff judgement, and fall history were used to classify the risk of falling in 208 residents (mean age $83.2 \pm 6.8$ years) living in four residential care facilities in northern Sweden. The MIF chart includes an observation of the ability to walk and simultaneously interact with a person or an object, a vision test, and a concentration rating. Staff rated each resident's risk as high or low and reported the resident's history of falls during the past 6 months. Falls were followed up for 6 months. Results: During the follow-up period, 104 residents (50\%) fell at least once indoors. Many of the factors commonly associated with falls did not differ significantly between residents who fell at least once and residents who did not fall. In this validating sample the predictive accuracy of the MIF chart was notably lower than in the developmental sample. A combination of any two of the MIF chart, staff judgement, and history of falls was more accurate than any approach alone; more than half of the residents classified as 'high risk' by two approaches sustained a fall within 3 months. Conclusions: Residents classified as 'high risk' by any two of the MIF chart, staff judgement, and history of falls should be regarded as particularly prone to falling and in urgent need of preventive measures.
\end{abstract}

(Aging Clin Exp Res 2003; 15: 51-59)

${ }^{\circ}$ 2003, Editrice Kurtis

\section{INTRODUCTION}

Falls constitute a serious problem for frail older people. In institutional care, i.e., residential care facilities and nursing homes, older people experience falls three times as often as in the community (1), and the risk of sustaining a hip fracture is substantially higher (2). It therefore seems a matter of urgency to find ways of preventing falls in this population.

Commonly, preventive measures are focused on individuals who are judged most likely to develop a disease or sustain an injury. To define individuals at risk of falling, numerous regression analysis models have presented various combinations of risk factors (3-11). Nevertheless, the results of these studies could be difficult to incorporate into daily practice, partly because of the multitude and inconsistency of the stated risk factors, and partly because of difficulties in interpreting and using the models. To combat this, some fall risk assessment tools have been developed in which risk factors for falls are added together and a score is obtained (12-21). However, these tools are aimed at fall prediction in certain settings and, to our knowledge, only two have been developed for predicting falls among older people in residential facilities: the Fall Risk Index (12) and the Mobility Interaction Fall (MIF) chart (22). None of them has been validated in an independent sample. A vital aspect of the development of a predictive tool is to consider whether the predictive value derived from the developmental sample is generalizable to similar samples in other locations (23).

We previously developed the MIF chart (22) which includes a test of the ability to walk and simultaneously interact with a person or an object, a vision test, and a concentration rating. The findings in the developmental study indicated a promising way of classifying older people in residential care facilities as having a high or low fall risk. The sensitivity was $85 \%$ (95\% CI: $75-92 \%)$, the specificity $82 \%$ (95\% CI: $72-90 \%$ ), the positive predictive

Key words: Elderly, fall risk prediction, falls, Mobility Interaction Fall chart, residential care.

Correspondence: L. Lundin-Olsson, Geriatric Medicine, Umeå University, SE-901 85 Umeå, Sweden.

E-mail: Lillemor.Lundin.Olsson@physiother.umu.se

Received November 26, 2001; accepted in revised form July 26, 2002. 


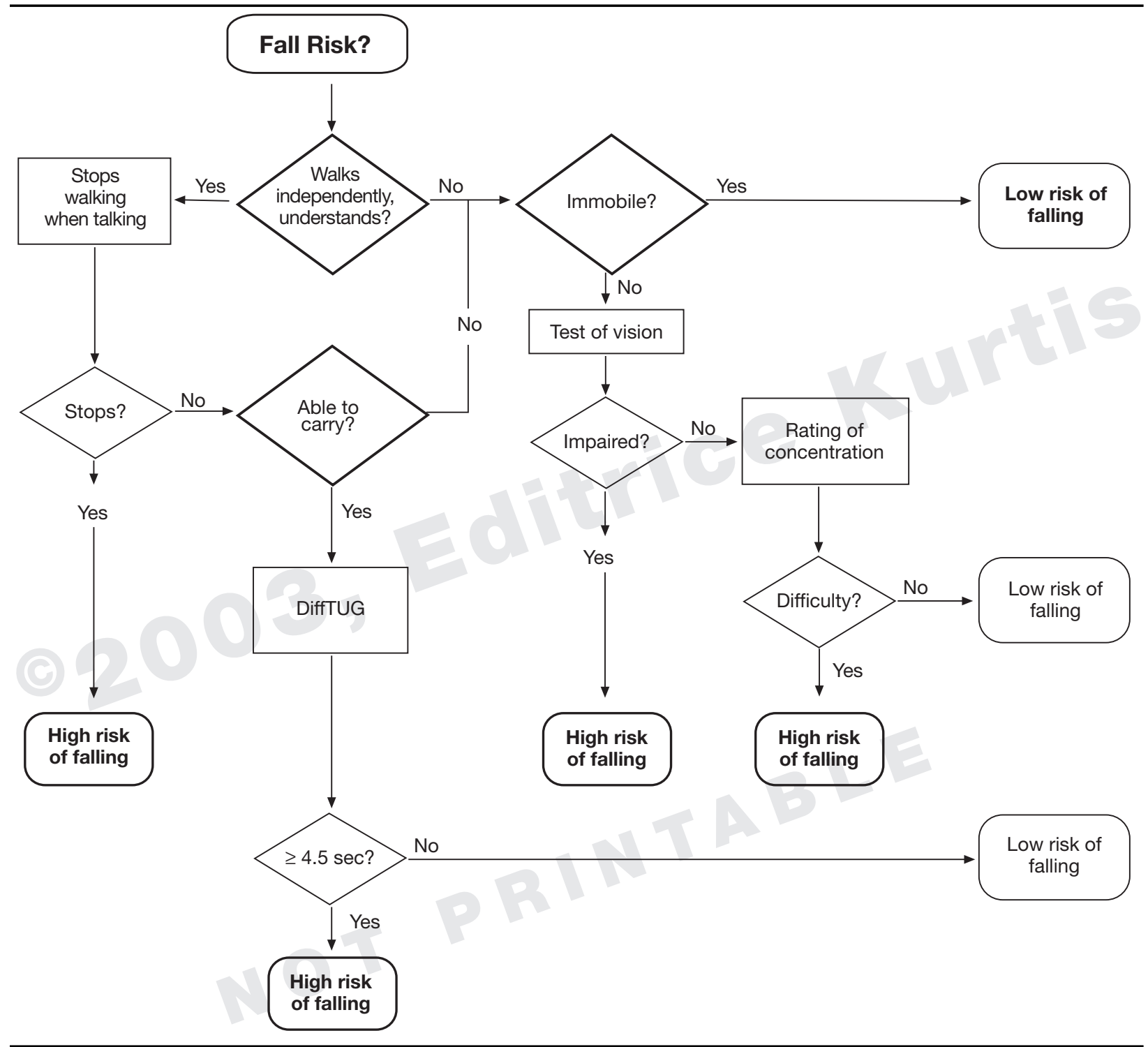

Figure 1 - The Mobility Interaction Fall (MIF) chart for assessing fall risk among older people in residential care facilities.

value $78 \%$ (95\% CI: $67-87 \%)$ and the negative predictive value was $88 \%$ (95\% CI: 79-95\%).

Some other ways of predicting falls have also been suggested. In numerous studies, previous falls have been associated with a higher risk of future falls (9-11, 24). In contrast with history of falls, staff judgement of the residents' risk of future falls appears to be a neglected topic. Only one small study has focused on this issue (25).

The main purpose of this study was to validate the predictive accuracy of the MIF chart in a new sample, and to compare it to staff judgement of fall risk and history of falls. A second purpose was to investigate whether a combination of these measures would increase fall prediction accuracy.

\section{METHODS}

\section{Participants and setting}

The participants were recruited from four residential care facilities in Umeå, a city in northern Sweden. All the residents $(\mathrm{N}=219)$, who were 65 years or older, were given oral and written information about the study. Information was also given to relatives of residents with substantial cognitive dysfunction. Eleven 
residents declined to participate. They were likely to be younger than the remaining 208 residents (mean age $78.7 \pm 5.5$ us $83.2 \pm 6.8$ years; $p=0.03$ ) but did not differ with regard to gender.

In Sweden, older adults living in residential care facilities are disabled by cognitive and/or physical impairment and thus require supervision or functional support and care. In these facilities (skilled nursing homes excluded) a majority of the residents are able to move independently between bed and chair as well as walk indoors, but only a minority use the stairs and leave the facility unsupervised. Some live in a private apartment and others in a private room with a shared dining and living room. There is no clear distinction in characteristics between residents living in an apartment or in a room. All residents have access to help with activities of daily living (ADL), housework, medical care, and supervision as required. At the facilities in the present study, nurses worked during the day and were on call at night. A specialist in geriatric medicine made planned weekly house calls as well as emergency ones. For further examination and treatment, residents were referred to the hospital.

The Ethical Committee at the Medical Faculty of the Umeå University approved the study.

\section{Baseline examination}

A specialist in geriatric medicine, who also was the resident's personal doctor, registered the diagnoses and current medication of each participant under his/her care. The majority of residents were well known to their doctors and the recording was based on previous knowledge and chart review. In total, six specialists were engaged in this study.

Six physiotherapists were employed in the study and trained to assess vision, hearing, cognition and fall risk. Hearing was rated as impaired if the resident, without a hearing aid, did not hear when the physiotherapist spoke in a normal voice from a distance of one meter. Vision was rated as impaired when the resident, with or without glasses, could not read a word written in $5 \mathrm{~mm}$ capital letters at normal reading distance. The Mini-Mental State Examination (MMSE) was used to assess cognitive function (26). A nurse at the facility answered a written question about episodes of delirium: 'Has the resident had episodes of delirium during the past month? Yes/No'.

The resident's risk of falling was classified by three different means: the MIF chart, the staff global rating of the resident's risk of future falls, and a history of falls as recalled by staff.

The physiotherapists assessed the residents' risk of falling using the Mobility Interaction Fall (MIF) chart (Fig. 1 ), a screening tool described in detail elsewhere (22). Briefly, the MIF chart has several 'exits' classifying the residents at either high or low risk of falling. The residents were screened for mobility at three levels (able to walk independently indoors, need of personal assistance to walk, and 'immobile') and for their ability to understand the instructions for the Timed Up\&Go test (TUG). The TUG is the time it takes to rise from a chair, walk 3 meters, turn, walk back and sit down again (27).

Residents who could walk independently and understand the instructions were observed for the SWWT (Stops Walking When Talking), i.e., whether they stop walking when an occasional conversation starts during a walk in a corridor (28). Those who could walk and concurrently

Table 1 - Putative factors associated with falls in residents who did not fall and who fell at least once during the 6-month follow-up.

\begin{tabular}{|c|c|c|c|}
\hline & $\begin{array}{l}\text { No fall } \\
N=104\end{array}$ & $\begin{array}{l}\text { Any fall } \\
N=104\end{array}$ & $p$-value* \\
\hline Age (years, mean $\pm S D$ ) & $82.4 \pm 6.2$ & $84.1 \pm 7.3$ & 0.07 \\
\hline Sex (female, \%) & 69 & 76 & 0.28 \\
\hline \multicolumn{4}{|l|}{ Signs } \\
\hline Impaired vision (\%) & 20 & 26 & 0.36 \\
\hline Impaired hearing (\%) & 30 & 27 & 0.49 \\
\hline $\begin{array}{l}\text { Episodes of delirium } \\
\text { past month (\%) }\end{array}$ & 17 & 26 & 0.08 \\
\hline Urinary incontinence (\%) & 33 & 30 & 0.58 \\
\hline \multicolumn{4}{|l|}{ Cognitive and functional status } \\
\hline MMSE score $(\mathrm{Md}, \mathrm{IQR})^{\dagger \dagger}$ & $\begin{array}{c}17.7 \\
13.0-24.0\end{array}$ & $\begin{array}{c}16.2 \\
12.0-22.0\end{array}$ & 0.16 \\
\hline $\begin{array}{l}\text { Timed Up\&Go } \\
(\text { sec, mean } \pm \text { SD)§ }\end{array}$ & $24.9 \pm 18.3$ & $31.7 \pm 19.0$ & 0.03 \\
\hline Barthel Index (Md, IQR) ${ }^{\dagger}$ & $\begin{array}{l}\text { 12.0 } \\
\text { 7.3-17.0 }\end{array}$ & $\begin{array}{l}12.5 \\
9.3-17.0\end{array}$ & 0.85 \\
\hline \multicolumn{4}{|l|}{ Diagnosis } \\
\hline Dementia (\%) & 30 & 43 & 0.05 \\
\hline Depression (\%) & 27 & 30 & 0.68 \\
\hline Previous stroke (\%) & 39 & 29 & 0.12 \\
\hline Heart failure (\%) & 35 & 28 & 0.72 \\
\hline Lung disease (\%) & 14 & 11 & 0.51 \\
\hline Osteoarthritis (\%) & 28 & 22 & 0.32 \\
\hline Femur fracture last year (\%) & 2 & 7 & 0.48 \\
\hline No. of diagnoses $(\mathrm{Md}, \mathrm{IQR})^{\dagger}$ & $2,1-3$ & $2,1-3$ & 0.92 \\
\hline \multicolumn{4}{|l|}{ Drugs } \\
\hline Diuretics (\%) & 58 & 46 & 0.10 \\
\hline Analgesics (\%) & 64 & 63 & 0.86 \\
\hline Laxatives (\%) & 47 & 59 & 0.10 \\
\hline Benzodiazepines (\%) & 27 & 39 & 0.06 \\
\hline Antidepressants (\%) & 34 & 34 & 1.00 \\
\hline Neuroleptics (\%) & 33 & 29 & 0.55 \\
\hline No. of drugs $(\mathrm{Md}, \mathrm{IQR})^{\dagger}$ & $6,4-8$ & $6,4-8$ & 0.63 \\
\hline
\end{tabular}

"Refers to the significance level of differences between residents with no fall and at least one fall. ${ }^{\dagger} \mathrm{Md}, \mathrm{IQR}=\mathrm{Median}$, range between $1^{\text {st }}$ and $3^{\text {rd }}$ quartile.

${ }^{\ddagger} 16$ residents not assessed because of aphasia or other medical reason. No fall: $\mathrm{N}=97$; any fall: $\mathrm{N}=95$. $\$ 68$ residents not able to perform the TUG. No fall: $\mathrm{N}=63$; any fall: $\mathrm{N}=77$. 


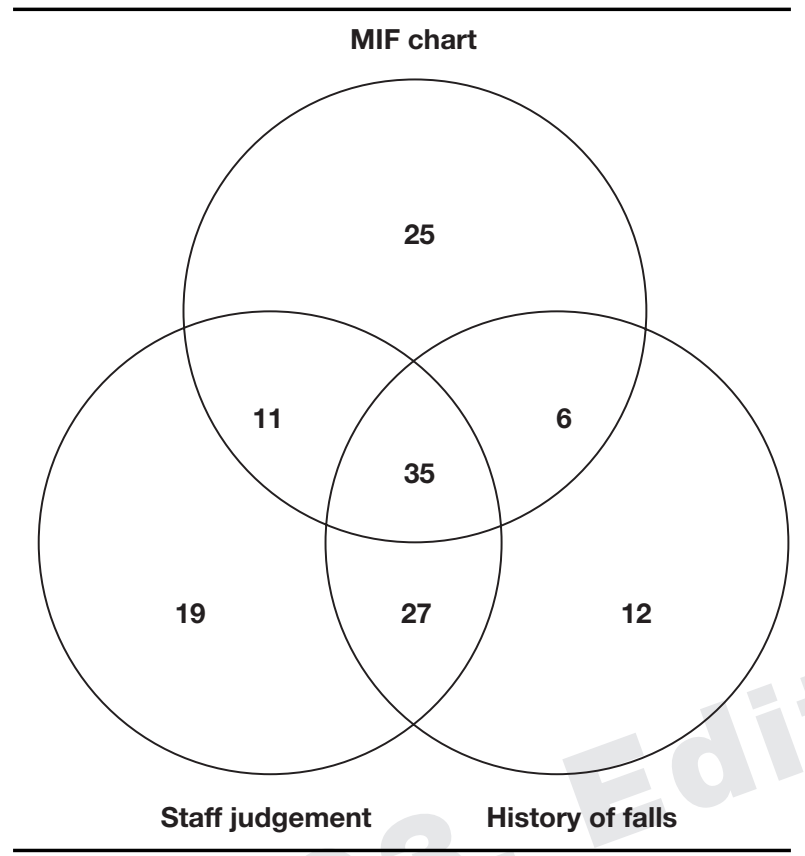

Figure 2 - Distribution of residents predicted to be at high risk of falling according to the Mobility Interaction Fall (MIF) chart, staff judgement and history of falls.

carry a glass were asked to do the TUG as fast as possible with and without carrying a glass containing $5 \mathrm{cL}$ of water. The difference in time between TUG without and with the glass is called the diffTUG (29). A high risk of falling is indicated for a resident who stops walking when talking or has a diffTUG of at least 4.5 seconds.

Residents who needed two helpers to transfer between chair and bed and sat in a wheelchair in a half-lying position or were long-term bedridden ('immobile') were classified as having a low fall risk.

Residents not previously classified who had impaired vision were classified as having a high risk of falling. The remaining residents were further rated for the ability to concentrate. Concentration difficulty was recorded when residents reported difficulties in following a TV program or reading an article or when they were observed to have trouble maintaining the thread of a conversation. Those with concentration difficulties were classified as high-risk.

The test-retest reliability of the MIF chart was evaluated in another - but similar - residential care facility. Participants were 4 physiotherapists employed in the present study and 50 residents, 16 men and 34 women, aged 6096 years (mean $83.7 \pm 7.5$ years). Two physiotherapists made independent ratings of the same resident on two consecutive days. For the total MIF-chart, there was $80 \%$ agreement between raters (22). For the individual components of the MIF chart, the agreement was $88 \%$ for the mobility screening and understanding of simple instructions, $94 \%$ for the SWWT observation, $100 \%$ for the rating of 'ability to carry' a glass, $74 \%$ for the diffTUG, $86 \%$ for the vision test, and $90 \%$ for the concentration rating.

Physiotherapists questioned nurses' aides and licensed practical nurses who knew the resident well, and had been selected by the head of each facility, about 1) fall risk: "How do you judge the risk that $\mathrm{Mr} / \mathrm{Ms} \mathrm{X}$ will fall within 6 months - high or low?", 2) ADL by means of the Barthel ADL Index $(30,31)$, and 3) history of falls: "Has Mr/Ms X sustained a fall indoors during the last 6 months?". The questions were asked in the same order.

\section{Reporting of falls}

The follow-up period was set $a$ priori at 6 months. A fall was defined as an event in which the resident unintentionally came to rest on the floor, regardless of whether or not an injury was sustained. This definition thus included falls as a consequence of acute illness such as a stroke or an epileptic seizure. Staff were instructed to register on a structured fall report every fall they observed, or when they found residents unaccountably on the floor or ground, or when the residents reported their own falls. The fall reports were collected once a week. In order to optimize the collection of fall reports, the residents' charts were reviewed after 3 months and at the end of the study. In these charts the staff was instructed to note important events such as a fall or a change in a resident's

Table 2 - The accuracy of fall risk prediction by the MIF chart, staff judgement, and history of falls.

\begin{tabular}{|c|c|c|c|c|c|c|c|c|}
\hline & \multicolumn{2}{|c|}{$\begin{array}{c}\text { Positive } \\
\text { predictive value* }\end{array}$} & \multicolumn{2}{|c|}{$\begin{array}{c}\text { Negative } \\
\text { predictive value }^{\dagger}\end{array}$} & \multicolumn{2}{|c|}{ Sensitivity ${ }^{\ddagger}$} & \multicolumn{2}{|c|}{ Specificity $\$$} \\
\hline & $\%$ & $\mathbf{N}$ & $\%$ & $\mathbf{N}$ & $\%$ & $\mathbf{N}$ & $\%$ & $\mathbf{N}$ \\
\hline MIF chart & 58 & $45 / 77$ & 55 & $72 / 131$ & 43 & $45 / 104$ & 69 & $72 / 104$ \\
\hline Staff judgement & 67 & $62 / 92$ & 64 & $74 / 115$ & 60 & $62 / 103$ & 71 & $74 / 104$ \\
\hline Fall history & 68 & $54 / 80$ & 61 & 77/127 & 52 & $54 / 104$ & 75 & $77 / 103$ \\
\hline
\end{tabular}

"Correctly classified as 'high risk' residents. †Correctly classified as 'low risk' residents. ंResidents classified as 'high risk'/all residents who fell. \$Residents classified as 'low risk'/all residents who did not fall. 
health status. We found notes for 25 falls, representing $8.6 \%$ of the total number of falls, which were not registered on a fall incidence report. These falls were also included in the analyses.

\section{Statistical analysis}

The follow-up period for falls lasted 6 months. For each resident, we calculated the number of observation days from inclusion to the end-point of the study or to the day when the resident changed residence or died. Also, for residents who had experienced a fall, we calculated the number of days from inclusion in the study to the first fall. Days (if more than 3) spent outside the facility were subtracted.

The incidence rate of falls was calculated as the number of fall events divided by the total number of observation days, expressed in 1000 person-days.

Resident characteristics at baseline are described for those who fell and those who did not fall during follow-up, and compared using Student's two-tailed t-test, MannWhitney U test, and the $\chi^{2}$ test.

Classifications according to the MIF chart, staff judgement and history of falls were first tested one by one; then they were tested in pairs, two by two; and finally all 3 combined. Thus, the scores of two means of classification (0-2) resulted in a low, an intermediate, and a high-risk group. The low-risk group included residents who were classified by both means as 'lowrisk' and the high-risk group included residents classified by both means as 'high-risk'. To be in the intermediate group, the resident was classified as 'high-risk' by one of the means. Using the same method of summation, the scores of the three means of classification (0-3) resulted in a low-risk group, two intermediate groups, and a high-risk group.

Two approaches to analyze the accuracy of the prediction were used: viewing the 6-month follow-up period in total and analyzing what happened within this period. First, the predictive values, sensitivity, and specificity were calculated. The outcome variable was 'fall' and 'no fall', and all 208 residents assessed at baseline were included. Second, the time to the first fall was analyzed by means of Kaplan-Meier survival curves, the log rank test, and the Cox proportional hazard model.

The statistical significance level was set at 0.05 , and the statistical analyses were computed by the SPSS software package, version 6.1 (32).

\section{RESULTS}

During the 6-month follow-up, 104 residents, representing $50 \%$ of the sample, fell at least once indoors and 57 residents $(27 \%)$ fell twice or more. The number of falls for each resident ranged from 0 to 16 . Seventeen residents died and 10 moved from the facility (13\%) during the follow-up. In total 290 falls were registered during 34837
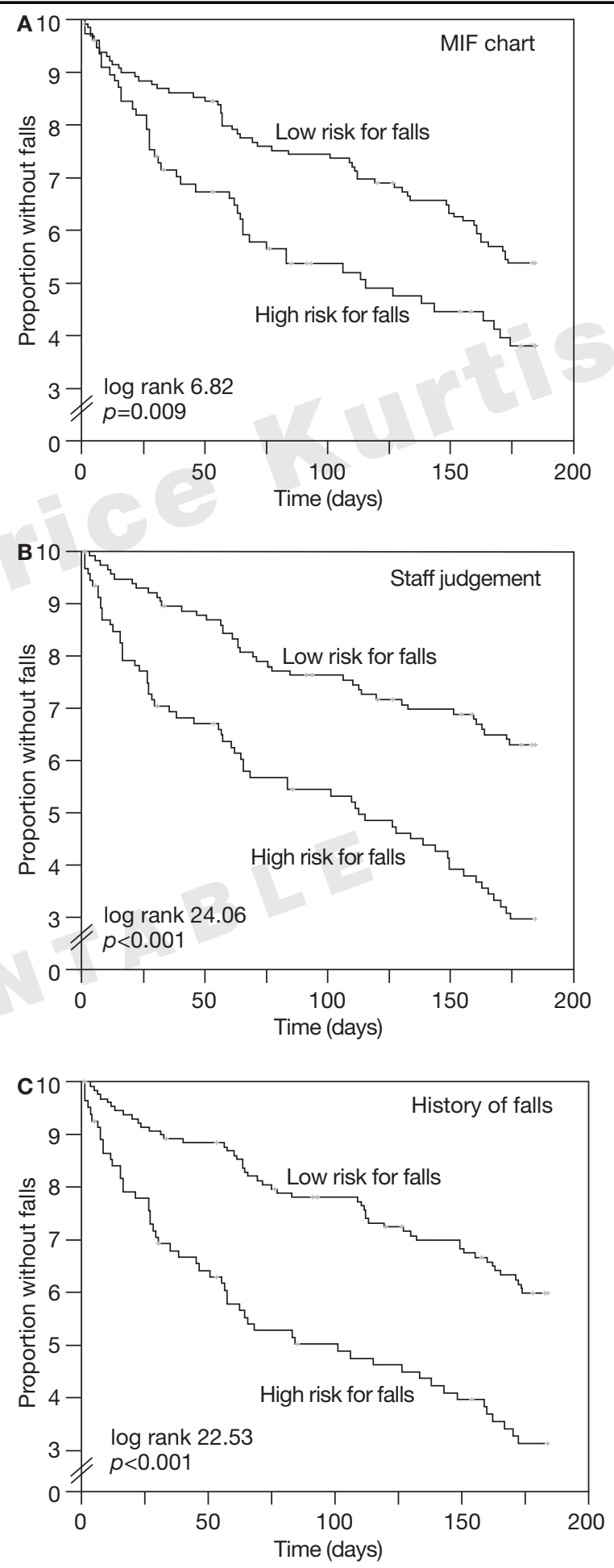

Figure 3a-c - Kaplan-Meier curves of the fall risk among older people in residential care facilities $(N=208)$ assigned to low- and high-risk groups by a) MIF chart, b) staff judgement, and c) history of falls. 

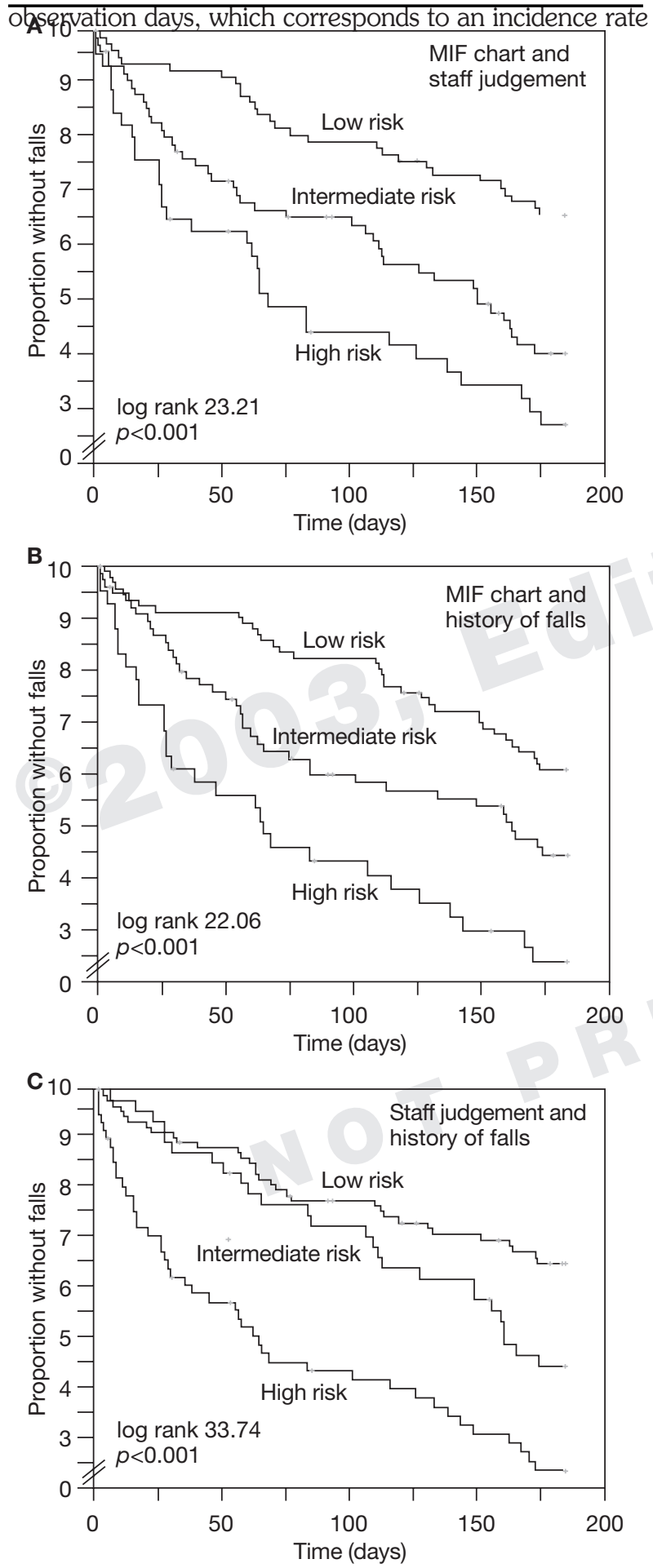

Figure 4a-c-Kaplan-Meier curves of the fall risk among older people in residential care facilities $(N=208)$ assigned to low, intermediate, and high-risk groups by a) MIF chart and staff judgement, b) MIF chart and history of falls, and c) staff judgement and history of falls. of 8.3 (95\% CI 8.2-8.5) falls per 1000 person-days.

The distribution of characteristics in the residents who did and those who did not fall during the follow-up did not differ significantly, with the exception of the Timed Up\&Go test (Table 1).

The MIF chart, staff judgement and history of falls classified a total of 135 residents as being at high risk of falling. The three methods classified the same resident in 35 cases (Fig. 2). Data were missing regarding one resident in 'staff judgement' and one in 'history of falls'.

\section{Prediction accuracy at 6 months}

For the whole 6-month period, the MIF chart resulted in lower sensitivity and predictive values than did staff judgement and history of falls (Table 2). Twenty-two residents who fell, representing $21 \%$ of the fallers, were not classified by any of the methods as being at high risk of falling.

\section{The MIF chart}

According to the MIF chart, residents were classified as being at high risk of falling when they 'stopped walking when talking' ( $\mathrm{N}=11 ; 55 \%$ fell), had a diffTUG of at least 4.5 seconds ( $\mathrm{N}=20 ; 45 \%$ fell), had impaired vision $(\mathrm{N}=25 ; 72 \%$ fell) or had concentration difficulties ( $\mathrm{N}=21$; $57 \%$ fell). Residents classified as 'low risk' had a shorter diffTUG ( $\mathrm{N}=61 ; 52 \%$ did not fall), were 'immobile' $(\mathrm{N}=21 ; 81 \%$ did not fall) or had no concentration difficulties ( $\mathrm{N}=49 ; 47 \%$ did not fall).

\section{Time to first fall}

Regardless of whether the MIF chart, staff judgement or history of falls was used, all the predicted high-risk groups differed significantly from the low-risk groups in the probability of sustaining a fall (Fig. 3a-c). The three pairwise combinations (MIF chart-staff judgement, MIF chart-history of falls, and staff judgement-history of falls) resulted in similar fall probabilities. In the 'high-risk' groups the median time without falls was 2 months in all combinations (Fig. 4a-c).

Table 3 shows that in 3 months, the residents classified as having a low risk had a fall probability of $22-26 \%$ depending on the classification method, and those classified as 'high-risk' had a probability of $46-51 \%$. The corresponding figures for fall risk in 6 months were increased further by approximately $20 \%$. In comparison with the low-risk group, the hazard ratio (HR) for a fall event ranged from 1.7 to 4.5 depending on the means of classification and combination.

\section{DISCUSSION}

The present validating study, with a follow-up period of 6 months, showed a lower predictive accuracy of the MIF chart than did the developmental study. The predictive value of the MIF chart, staff judgement, and history of falls did not differ significantly. A combination of any two 
methods was more accurate than any method alone; more than half of the residents classified as 'high risk' by both approaches sustained a fall within 3 months.

The methods used to derive predictive models and scoring tools are dependent on the data of the developmental sample so the predictive performance in a new sample is expected to be overly optimistic (23). To our knowledge, only six of many published predictive models and fall risk assessment tools were tested prospectively in a new sample. All of them are directed at identifying patients falling in hospitals (14, 21, 25, 33-35). As a consequence of validation, one of the tools was modified substantially with half of the factors changed (35). Regarding the others, data are provided for three of them so that a comparison of sensitivity, specificity, and predictive values can be made between the first and the second testing and a reduction is seen $(21,33,34)$. Also regarding the MIF chart, the high predictive values in the developmental sample were not repeated in the validating sample. There was a change in the sensitivity from 85 to
$43 \%$, in the specificity from 82 to $69 \%$, in the positive predictive value from 78 to $58 \%$, and in the negative predictive value from 88 to $55 \%$.

Apart from case-mix differences between the developmental and validating samples, there are several possible reasons for a reduced predictive performance in a new testing process (23). One important factor is the definition of a fall. In the present study all indoor falls were counted, including occasions when the residents were unaccountably found on the floor and falls due to loss of consciousness or sudden paralysis. We consider it of great importance to include all falls because among frail old persons the cause of a fall may be difficult to identify. Most falls are unwitnessed and the resident who fell may have trouble in remembering or describing the circumstances of the fall. In addition, there is a risk of injury every time someone's body unintentionally lands on the floor, regardless of the cause. As a consequence of this definition, the developmental sample as well as the validating sample probably included falls not predictable with the use of

Table 3 - Hazard ratio and the probability of falling according to the classification of fall risk by use of the MIF chart, staff judgement, history of falls and combinations.

\begin{tabular}{|c|c|c|c|c|c|}
\hline & $\begin{array}{c}\text { Residents at } \\
\text { baseline } \\
\mathbf{N}\end{array}$ & $\begin{array}{l}\text { Fall events } \\
\text { in } 6 \text { months } \\
N\end{array}$ & $\begin{array}{c}\text { Hazard ratio } \\
(95 \% \mathrm{CI})\end{array}$ & in $\begin{array}{c}\text { Probabil } \\
\text { months }\end{array}$ & $\begin{array}{c}\text { ity of falls } \\
\text { in } 6 \text { months } \\
\%\end{array}$ \\
\hline \multicolumn{6}{|l|}{ MIF chart } \\
\hline Low risk & 131 & 59 & 1.0 & 26 & 46 \\
\hline High risk & 77 & 45 & $1.7(1.1-2.5)$ & 46 & 62 \\
\hline \multicolumn{6}{|l|}{ Staff judgement } \\
\hline Low risk & 115 & 41 & 1.0 & 24 & 47 \\
\hline High risk & 92 & 62 & $2.6(1.7-3.9)$ & 46 & 70 \\
\hline \multicolumn{6}{|l|}{ History of falls } \\
\hline Low risk & 127 & 50 & 1.0 & 22 & 41 \\
\hline High risk & 80 & 54 & $2.5(1.7-3.6)$ & 51 & 70 \\
\hline \multicolumn{6}{|c|}{ MIF chart+Staff judgement } \\
\hline Low risk & 84 & 28 & 1.0 & 20 & 34 \\
\hline Intermediate risk & 77 & 43 & $2.2(1.4-3.5)$ & 35 & 60 \\
\hline High risk & 46 & 32 & $3.3(2.0-5.5)$ & 56 & 73 \\
\hline \multicolumn{6}{|c|}{ MIF chart+History of falls } \\
\hline Low risk & 91 & 35 & 1.0 & 18 & 40 \\
\hline Intermediate risk & 75 & 39 & $1.7(1.1-2.7)$ & 40 & 56 \\
\hline High risk & 41 & 30 & $3.2(1.9-5.2)$ & 57 & 76 \\
\hline \multicolumn{6}{|c|}{ Staff judgement + History of falls } \\
\hline Low risk & 95 & 32 & 1.0 & 22 & 35 \\
\hline Intermediate risk & 48 & 26 & $1.7(1.03-2.9)$ & 27 & 56 \\
\hline High risk & 62 & 45 & $3.6(2.3-5.6)$ & 57 & 77 \\
\hline \multicolumn{6}{|c|}{ Staff judgement + History of falls + MIF chart } \\
\hline Low risk & 71 & 22 & 1.0 & 19 & 32 \\
\hline Intermediate risk 1 & 56 & 28 & $1.9(1.1-3.3)$ & 27 & 53 \\
\hline Intermediate risk 2 & 44 & 26 & $2.7(1.5-4.8)$ & 45 & 63 \\
\hline High risk & 35 & 27 & $4.5(2.6-8.0)$ & 61 & 80 \\
\hline
\end{tabular}


predisposing factors like those in the MIF chart. These falls would have had an adverse effect on the predictive accuracy of the MIF chart.

When the screening is completed by persons other than those who developed the method, the reliability of the assessment and consequently the predictive performance may be reduced $(21,23)$. When developing the MIF chart, the assessments of mobility were carried out in a certain room, the same for all residents, by three physiotherapists always working in pairs. They could thus reach a consensus on how to demonstrate and instruct residents about the measures. The vision test and rating of concentration were performed by two physicians. In the validation, all the assessments were carried out in the resident's home or in a corridor by one of the six physiotherapists in the study. This approach with new settings and different assessors poses a great challenge to the prognostic accuracy. Despite the obvious risk of increasing the variability of the prediction, we emphasize that it is of great importance to validate a measure in a way that represents how it is meant to be used in daily practice.

The MIF chart, staff judgement, and history of falls did in part identify the residents' fall risk in the same way, but there was also a considerable difference. In research concerning the prediction of falls, the most common method in use is to investigate probable predisposing factors at one particular point in time, after which the occurrence of falls is monitored for a certain time. This method was also used in developing the MIF chart but it might be insufficient in residential care facilities because of the fluctuating function in many residents. In the present sample, $22 \%$ of the residents had experienced episodes of delirium during the last month. An assessment made only once may give a restricted picture of predisposing factors for falling. In contrast, staff who know the resident well have knowledge that has been gained over time and they would thus perceive frequently occurring changes in function and in the diurnal rhythm. In the present study, staff had not been offered any information on how to identify residents at risk of falling. Also, they were asked how they estimated the residents' fall risk without any preceding discussion about the residents' health and abilities. In some cases, the classification according to 'staff judgement' and 'history of falls' differed. Knowledge of risk factors might promote awareness of the fall problem as well as increase the predictive accuracy of staff judgement.

A combination of any two of the MIF chart, staff judgement, and history of falls was more accurate than any approach alone; more than half of the residents classified as 'high risk' by two approaches sustained a fall within 3 months. This option to combine methods may entail certain advantages: when staff who have been working at the facility for 6 months are present they can score previous falls, when staff who know the resident are present they can estimate the risk of future falling, and the assessment by the MIF chart only takes a short time to carry out. Previously, Wyatt and Altman (36) pointed out the probable benefits of having a combination of predisposing factors and, in their case, a physician's own estimate of prognosis.

An obvious matter of concern in this study is the interrater reliability of staff judgement of fall risk and the recollection of previous falls. Nevertheless, staff judgement of fall risk has been a neglected topic and may be a relevant contributor to the future prevention of falls, either alone or incorporated into a formal risk assessment. Clearly, replication is needed in another location, with respect to both prognostic validity and reliability.

\section{CONCLUSIONS}

In conclusion, the incidence of falls is high in the group of older people living in residential care facilities. Very few putative risk factors for falling differ between those who fall and those who do not, which makes it difficult to identify residents prone to falling in this kind of setting. However, combinations of staff judgement of fall risk, staff knowledge of previous falls and/or the MIF chart can identify many of those who are at particularly high risk of falling. These residents should be regarded as being in urgent need of preventive measures.

\section{ACKNOWLEDGEMENTS}

The authors thank the Social Authorities of the municipality of Umea for their fruitful cooperation, the participants, physicians G. Bucht, I. Bylén, A. Byström, B. Hermansson, P-O. Österlind, and physiotherapists S. Eriksson, L. Frick, C. Gruffman, E. Nordin, E. Rosendahl and M. Östensson. This work was supported by grants from the County Council of Västerbotten, the Federation of County Councils in Sweden, the Umeå University Foundation of Medical Research, the Gun and Bertil Stohnes' Foundation, and the Swedish Foundation for Health Care Sciences and Allergy Research.

\section{REFERENCES}

1. Luukinen H, Koski K, Hiltunen L, Kivelä S-L. Incidence rate of falls in an aged population in Northern Finland. J Clin Epidemiol 1994; 47: 843-50.

2. Butler M, Norton R, Lee-Joe T, Cheng A, Campbell AJ. The risks of hip fracture in older people from private homes and institutions. Age Ageing 1996; 25: 381-5.

3. Robbins AS, Rubenstein LZ, Josephson KR, Schulman BL, Osterwiel D, Fine G. Predictors of falls among elderly people. Results of two population-based studies. Arch Intern Med 1989; 149: 1628-33

4. Lipsitz LA, Jonsson PV, Kelley MM, Koestner JS. Causes and correlates of recurrent falls in ambulatory frail elderly. J Gerontol 1991; 46: M114-22.

5. Tinetti ME, Doucette J, Claus E, Marottoli R. Risk factors for serious injury during falls by older persons in the community. J Am Geriatr Soc 1995; 43: 1214-21.

6. Tinetti ME, Doucette JT, Claus EB. The contribution of predisposing and situational risk factors to serious fall injuries. $\mathrm{J} \mathrm{Am}$ Geriatr Soc 1995; 43: 1207-13.

7. Luukinen H, Koski K, Laippala P, Kivela SL. Predictors for re- 
current falls among the home-dwelling elderly. Scand J Prim Health Care 1995; 13: 294-9.

8. Luukinen H, Koski K, Laippala P, Kivela SL. Risk factors for recurrent falls in the elderly in long-term institutional care. Public Health 1995; 109: 57-65.

9. Graafmans WC, Ooms ME, Hofstee HMA, Bezemer PD, Bouter LM, Lips P. Falls in the elderly: A prospective study of risk factors and risk profiles. Am J Epidemiol 1996; 143: 1129-36.

10. Thapa PB, Brockman KG, Gideon P, Fought RL, Ray WA. Injurious falls in nonambulatory nursing home residents: a comparative study of circumstances, incidence, and risk factors. J Am Geriatr Soc 1996; 44: 273-8.

11. Kiely DK, Kiel DP, Burrows AB, Lipsitz LA. Identifying nursing home residents at risk for falling. J Am Geriatr Soc 1998; 46: 551-5.

12. Tinetti ME, Williams TF, Mayewski R. Fall risk index for elderly patients based on a number of chronic disabilities. Am J Med 1986; 80: 429-34.

13. Morse JM, Morse RM, Tylko SJ. Development of a scale to identify the fall-prone patient. Can J Aging 1989; 8: 366-77.

14. Schmid NA. 1989 Federal Nursing Service Award Winner. Reducing patient falls: a research-based comprehensive fall prevention program. Mil Med 1990; 155: 202-7.

15. Heslin K, Towers J, Leckie C, et al. Managing falls: Identifying population-specific factors and prevention strategies. In Funk SG, Tornquiest EM, Champagne MT, Weise RA, Eds. Key aspects of elder care: Managing falls, incontinence, and cognitive impairment. New York: Springer Pub. Co, 1992.

16. Downton JH. Falls in the elderly. London: Edward Arnold, 1993.

17. Studenski S, Duncan PW, Chandler J, et al. Predicting falls: The role of mobility and nonphysical factors. J Am Geriatr Soc 1994; 42: 297-302.

18. Hendrich A, Nyhuis A, Kippenbrock T, Soja ME. Hospital falls: development of a predictive model for clinical practice. Appl Nurs Res 1995; 8: 129-39.

19. MacAvoy S, Skinner T, Hines M. Fall risk assessment tool. Appl Nurs Res 1996; 9: 213-8.

20. Nyberg L, Gustafson Y. Fall prediction index for patients in stroke rehabilitation. Stroke 1997; 28: 716-21.

21. Oliver D, Britton M, Seed P, Martin FC, Hopper AH. Develop- ment and evaluation of evidence based risk assessment tool (STRATIFY) to predict which elderly inpatients will fall: case-control and cohort studies. BMJ 1997; 315: 1049-53.

22. Lundin-Olsson L, Nyberg L, Gustafson Y. The Mobility Interaction Fall Chart. Physiother Res Int 2000; 5: 184-95.

23. Altman DG, Royston $P$. What do we mean by validating a prognostic model? Stat Med 2000; 19: 453-73.

24. Myers AH, Baker SP, Van Natta ML, Abbey H, Robinson EG. Risk factors associated with falls and injuries among elderly institutionalized persons. Am J Epidemiol 1991; 133: $1179-90$.

25. Moore T, Martin J, Stonehouse J. Predicting falls: Risk assessment tool versus clinical judgement. Perspectives 1996; 20: 8-11.

26. Folstein MF, Folstein SE, McHugh PR. Mini-mental state: A practical method for grading the cognitive state of the patient for the clinician. J Psychiatr Res 1975; 12: 189-98.

27. Podsiadlo D, Richardson S. The Timed "Up \& Go": a test of basic functional mobility for frail elderly persons. J Am Geriatr Soc 1991; 39: 142-8.

28. Lundin-Olsson L, Nyberg L, Gustafson Y. "Stops walking when talking" as a predictor of falls in elderly people. Lancet 1997; 349: 617.

29. Lundin-Olsson L, Nyberg L, Gustafson Y. Attention, frailty, and falls: the effect of a manual task on basic mobility. J Am Geriatr Soc 1998; 46: 758-61.

30. Mahoney FI, Barthel DW. Functional evaluation: the Barthel Index. Maryland State Med J 1965; 14: 61-5.

31. Wade DT, Collin C. The Barthel ADL index: a standard measure of physical disability? Intern Disabil Stud 1988; 10: 64-7.

32. Norusis MJ. SPSS advanced statistics 6.1. United States of America: SPSS Inc., 1994.

33. Morse JM, Black C, Oberle K, Donahue P. A prospective study to identify the fall-prone patient. Soc Sci Med 1989; 28: 81-6.

34. Nyberg L, Gustafson Y. Using the Downton Index to predict those prone to falls in stroke rehabilitation. Stroke 1996; 27: 1821-4.

35. Rutledge DN, Donaldson NE, Pravikoff DS. Fall risk assessment and prevention in healthcare facilities. The Online Journal of Clinical Innovations 1998; 1: 1-33.

36. Wyatt JC, Altman D. Prognostic models: clinically useful or quickly forgotten? BMJ 1995; 311: 1539-41. 